Revista Latinoamericana de la Papa 23 (1): 56 - 62, 2019

ISSN: 1853-4961

http://ojs.papaslatinas.org/index.php/rev-alap/index

\title{
Caracterización de los semilleristas tradicionales de papa en Bolivia
}

\author{
X. Cadima ${ }^{1 / *} ;$ F. Terrazas ${ }^{1}$
}

Recibido: $21 / 04 / 2019$

Aceptado: 04/06/2019

Accesible en línea: Junio de 2019

\section{Resumen}

La papa es un alimento estratégico para la soberanía alimentaria y la economía de miles de familias de los Andes bolivianos que se dedican a la producción de este cultivo. El sistema tradicional de semilla es el que provee más del $90 \%$ de la semilla requerida para el cultivo de la papa en Bolivia, y de un portafolio mayor de variedades que el que ofrece el sistema formal. Los agricultores encargados de la producción tradicional de semilla de papa, son por lo general agricultores que se destacan de otros productores en aspectos personales, pero también por su accesibilidad a entornos ecológicos y productivos que les permiten producir semilla de calidad. Los semilleristas también actúan en base a incentivos, que no son necesariamente monetarios y que van cambiando de acuerdo al contexto y entorno ambiental, social, económico y político, lo cual también influye en las perspectivas (amenazas y oportunidades) del agricultor semillerista de los Andes bolivianos. En este documento se hace una revisión de estos aspectos que caracterizan a los semilleristas tradicionales de papa y una reflexión de lo que se necesita reforzar para que continúen con su labor.

Palabras clave adicionales: Semilla de papa, sistema tradicional, semilleristas altoandinos.

\section{Characterization of traditional potato seed producers in Bolivia}

\section{Summary}

The potato is strategic for food sovereignty and the economy of thousands of families in the Bolivian Andes who are dedicated to the production of this crop. The traditional seed system provides more than $90 \%$ of the seed required for potato cultivation in Bolivia, and also a larger variety of varieties than the formal seed system offers. Farmers in charge of traditional potato seed production are usually farmers who stand out from other growers in personal aspects, but also because of their accessibility to ecological and productive environments that allow them to produce quality seed. Seed growers also act on the basis of incentives, which are not necessarily monetary and that are changing according to the context and environmental, social, economic and political environment, which also influence the perspectives (threats and opportunities) of the seed farmer of the Bolivian Andes. This document reviews these aspects that characterize traditional potato seed producers and a reflection of what needs to be reinforced is suggested so that seed growers can continue with their work.

\footnotetext{
* Autor para correspondencia. E-mail: x.cadima@proinpa.org

${ }^{1}$ Fundación PROINPA, Casilla 4285, Cochabamba, Bolivia.
} 
Additional keywords: Potato seed, traditional system, high-Andean seed producers

\section{Introducción}

La papa es el rubro de mayor contribución económica del sector campesino del área andina en Bolivia. Este rubro tiene una incidencia significativa en la generación de ingresos, contribuyendo al empleo y se constituye en una importante fuente de alimento de la población. A nivel nacional, es el cuarto rubro con mayor producción después de la caña de azúcar, la soya y el maíz, y también cuarto con mayor superficie cultivada después de la soya, el maíz y el girasol (INE 2016).

La oferta actual de semilla certificada constituye apenas el $5 \%$ del requerimiento anual de semilla de papa en Bolivia. El sistema tradicional de semilla, por otra parte, tiene alta capacidad de difundir semilla económicamente accesible y de un portafolio amplio de variedades que en Bolivia varía por regiones. Los agricultores tienen tecnologías que les ayudan a mantener la calidad de la semilla, pero no todos siguen las mejores prácticas y existen deficiencias generales que han generado una duda preocupante sobre la calidad de la semilla proveniente del sistema tradicional sin importar la procedencia o variedad (Thiele, 1999). No obstante, el sistema tradicional ofrece semilla de variedades que los agricultores quieren, a través de canales que ellos conocen (de Hann, 2009). En este documento se hace referencia a las características y argumentos que hacen que los semilleristas tradicionales continúen con su labor de proveedores de semilla al sistema papero de Bolivia.

\section{¿Qué rasgos distinguen al productor de} semillas?

\section{Aspectos personales}

En el sistema tradicional de semillas, los productores involucran a la familia entera, en el que cada miembro tiene roles específicos. Por ejemplo, la selección, mantenimiento y el control de calidad de la semilla está normalmente a cargo de la mujer. Este rol parece ser intrínseco a la mujer desde épocas pre-hispánicas en las diferentes culturas y con diferentes cultivos (Tapia y De la Torre, 1997; Conlago et al. 2011; Díaz y Azurdia 2001). Los niños ayudan a la madre en estas labores. El hombre se encarga del cultivo en campo, la cosecha y el transporte.

Los semilleristas tienen una tradición semillera que se ha construido en varias generaciones, por lo que cuentan con un prestigio especial y confianza ante el resto de los miembros de la comunidad donde pertenecen. El manejo de la semilla es una práctica adquirida por conocimiento tradicional. Los nuevos semilleristas, los de reciente formación, son los que en base a una mayor apertura a nuevos conocimientos y habilidades, también ganan prestigio de su comunidad.

\section{Aspectos ecológicos y productivos}

Los productores de semilla para denominarse como tal deben contar con terrenos ubicados en zonas aptas para la producción y multiplicación de semilla. Estas zonas están ubicadas a más $3500 \mathrm{~m}$ de altitud en la puna altoandina, deben ser terrenos sanos, es decir libre de todo tipo de patógenos, mejor si son vírgenes pero también se aceptan terrenos con varios años de descanso (al menos 5), esta condición es para asegurar una fertilidad y sanidad adecuada de los suelos 
destinados a la producción de semilla (Rioja y Barea 2004). En otros términos los semilleristas son los que cuentan con los mejores terrenos para la producción de papa de su comunidad.

En el caso de que un productor desee acceder a la certificación oficial de la semilla producida, sus terrenos deben estar certificados (por la autoridad competente) libres de enfermedades tales como machitez bacteriana (Ralstonia solanacearum), verruga (Sinchytrium endobioticum), carbón (Thecaphora solani) y plagas como los nematodos (Nacobbus aberrans, Globodera pallida, G. rostochiencis y Meloidogyne). Algunas enfermedades son permisibles pero a muy bajas incidencias, tales como rizoctonia (Rhizoctonia solani), sarna, (Spongospora subterranea), roña (Streptomyces scabies) y pierna negra (Erwinia carotovora) (Plata et al. 2016, Rioja y Barea 2004).

El material base para la producción y multiplicación de semilla en estos terrenos debe ser de la más alta calidad fitosanitaria posible (Hidalgo et al. 1997), los tubérculos deben ser de tamaño pequeño (como un huevo), con brotes cortos, uniformes y robustos. Los productores semilleristas recurren a fuentes tradicionales o no formales de semilla de papa para adquirir material base para la producción de semilla. Un buen productor realiza una selección rigurosa de la semilla adquirida, por lo tanto tiene mejores habilidades técnicas que otros agricultores para la selección ya sea de su propia cosecha o bien de otros lugares tradicionales de donde obtiene por transacción monetaria, a través del trueque o del intercambio de semilla por semilla, como regalo, préstamo, pago por trabajo, etc.

Idealmente para iniciar una producción certificada, el origen de la semilla debe ser óptimamente de calidad pre-básica (se obtiene en laboratorio de tejidos vegetales libres de virus) (Hidalgo et al. 1997). El costo de esta semilla es muy alto (Bs. $250 / \mathrm{kg}$ o \$us 36/kg), prácticamente inaccesible para los pequeños productores. Sin embargo, los semilleristas modernos han comprendido que vale la pena el esfuerzo y en varios casos, aunque no logran contar con recursos para semilla pre-básica, se esfuerzan para adquirir semilla certificada de calidad inferior a la pre-básica pero todavía con excelente calidad sanitaria. En contados casos, algunos productores adquieren unos pocos kilos de pre-básica cada año. Éstos son llamados "agricultores progresistas" porque aprecian una buena inversión.

Debido a los costos que implica el proceso de certificación de semilla y el riesgo de que durante el proceso de certificación los campos semilleros y/o la semilla producida sea rechazada por la autoridad certificadora, en varios casos, los productores optan por adoptar un proceso semi-formal para producir semilla artesanal (Bentley et al. 2002). Éste proceso consiste en adquirir semilla base certificada del sistema formal, seguir las recomendaciones de producción formal, pero no hacer certificar la producción de semilla obtenida. Bajo este proceso, los productores garantizan que la semilla producida sigue siendo de buena calidad aunque no tenga el sello del sistema formal.

El almacenamiento de la semilla de papa debe realizarse bajo condiciones diferentes a la papa consumo, es decir en ambientes aireados y con luz difusa (la papa consumo no debe recibir luz para evitar el verdeado) (Rioja y Barea 2004, Bentley et al. 2002). Los semilleristas tradicionales suelen almacenar su semilla en silos rústicos, ya sea en sus casas en 
phinas en un rincón con paja y hierbas repelentes de plagas, o también cerca de las viviendas en huecos o trojes que se preparan en el suelo y cubiertos con paja, hierbas repelentes y tierra. Los semilleristas "modernos" con el apoyo de proyectos de desarrollo, tienen acceso a silos construidos con las características recomendables para almacenar semilla de calidad.

\section{Incentivos para el productor semillerista}

\section{Incentivos tradicionales}

La producción de semilla normalmente requiere mayor inversión de tiempo y esfuerzo, lo cual es a la vez un incentivo para los productores semilleristas porque acceden a mano de obra adicional para cubrir los requerimientos del proceso de producción, y porque al ampliar las relaciones sociales con esta actividad, también pueden acceder a semilla de otras variedades o incluso de diferentes cultivos.

Las relaciones sociales de producción y reciprocidad se fortalecen, tales como el ayni, que consiste en la prestación recíproca de la fuerza de trabajo en las épocas de cosecha y siembra; la minga, que es una prestación de fuerza de trabajo por productos; y la umaraka, que consiste en la prestación de la fuerza de trabajo por comida y por bebida (Aramayo 2007).

\section{Incentivos actuales}

Debido a la importancia económica y social de la papa en Bolivia, la demanda por semilla es constante, no solo para las áreas tradicionales de cultivo de la parte andina, sino también para cultivo de invierno de los valles bajos mesotérmicos del país. La producción para el periodo 2005-2007 se realizó en una superficie estimada de 126.943 ha (Zeballos et al. 2009). Esta referencia permite estimar que el requerimiento aproximado de semilla a nivel nacional es de aproximadamente 190.000 t de semilla por año considerando que se emplea en promedio 1,5 t de semilla por hectárea.

Los beneficios monetarios por la venta de semilla son atractivos para los productores semilleristas, cuando tienen las posibilidades de insertar la semilla a mercados locales y regionales. Según cálculos recientes, se estima que los costos de producción de semilla se incrementan hasta un $10 \%$ respecto a los costos de producción de papa consumo, lo cual es significativo para los pequeños productores que tienen que adquirir material base de alta calidad para el proceso de producción de semilla, pero en compensación podrían generar más ingresos (incluso el doble) por la venta de semilla respecto a la papa consumo ${ }^{2}$.

La producción de semilla sana y de diversidad aumenta el valor de la zona semillera, porque abre posibilidad a mayores inversiones, por ejemplo para mejorar condiciones para los pobladores con acceso a servicios básicos, electricidad, caminos, puentes, infraestructura para agua de riego, etc.

\section{Perspectivas del agricultor semillerista}

\section{Amenazas}

Las consecuencias del cambio climático y la variabilidad climática no predecible, como la irregularidad de las lluvias (cambios en el patrón de precipitación y mayor intensidad en tiempos más reducidos), hacen los sistemas productivos más vulnerables por la

\footnotetext{
${ }^{2}$ Según datos del Reporte técnico 2015. Proyecto Mejora de los sistemas de semillas para la seguridad alimentaria de los pequeños productores - Componente Bolivia. Fundación PROINPA.
} 
dependencia prácticamente total de la producción con las condiciones del clima.

Las condiciones climáticas dadas durante un ciclo agrícola también influyen en el precio de la semilla de papa. Cuando es un "año bueno", existe buena producción, hay mucha oferta por los excedentes generados, lo cual hace disminuir el precio. En "años malos", hay poca producción, mucha demanda, y por lo tanto, se incrementan los precios (Aramayo 2007).

También está el peligro de la reducción de áreas semilleras tradicionales por problemas de sanidad de suelos. Según estudios recientes se ha verificado que enfermedades antes no presentes en zonas altoandinas por encima los $3000 \mathrm{~m}$ de altitud, debido entre otros, a cambios del clima, ya están afectando esos suelos, es el caso de la enfermedad de la marchitez bacteriana que antes se encontraba solo en valles de Bolivia ( $<2300 \mathrm{~m}$ de altitud) ahora se encuentra en zonas altas (puna, altiplano, cabeceras de valle) (Castillo y Plata, 2016; Plata et al., 2016). En algunas situaciones no es posible detectar esta enfermedad porque es asintomática en zonas altas, pero el problema se incrementa cuando la semilla de esas zonas llega a áreas bajas de producción de papa comercial. Una vez que la marchitez infecta suelos semilleros, queda descartado como zona productora de semilla.

La normativa actual tan estricta sobre certificación de semilla es un desincentivo para los productores, porque la realidad es que prácticamente todos los suelos productores de papa de consumo están afectados con problemas fitosanitarios. Muchos suelos tradicionales de producción de semilla han quedado descalificados por la normativa actual por la presencia plagas y enfermedades aunque estén en porcentajes muy bajos.

El movimiento indiscriminado de semilla entre diferentes zonas altas y bajas, impulsado por comerciantes inescrupulosos, hace que haya una mayor difusión también de enfermedades llegando a afectar las zonas semilleras.

La topografía accidentada de las zonas paperas y las malas condiciones de las vías de comunicación (Aramayo 2007) hacen que el transporte se encarezca incidiendo en los altos costos de producción de la semilla.

Otra amenaza es la alta migración de los agricultores de las áreas rurales a las ciudades y el subsecuente abandono del campo. Situación que está dejando solo personas mayores o población económicamente no activa en el campo ${ }^{3}$.

\section{Oportunidades}

El cambio climático por otra parte, al menos en el caso de la papa, está ocasionando que se amplíe las zonas de cultivo a áreas más altas debido a que las condiciones climáticas son menos drásticas que antes debido a un incremento de la temperatura (Jarvis et al. 2008). Esas zonas eran usualmente dedicadas al pastoreo, son suelos vírgenes con abundante materia orgánica, por lo tanto aptas para la producción de semilla de papa.

El contexto político y social actual en Bolivia que favorece a una mayor apertura al aprovechamiento de productos nativos, también es una oportunidad para ampliar el portafolio de variedades y de diversidad nativa, y por lo tanto para

\footnotetext{
${ }^{3}$ Antes de la Reforma Agraria de 1952 la población rural en el país era del $74 \%$, a la fecha esta población se redujo a menos del 33\% (Datos Censo Poblacional 2012, INE)
} 
demandar semilla de esos productos que normalmente están en las manos de los pequeños productores semilleristas. $\mathrm{La}$ conservación de la biodiversidad, los recursos genéticos y la revalorización de los saberes locales son componentes sustancialmente incorporados en las estrategias y política pública como la Ley 144 de Revolución Productiva Comunitaria, y la Ley 300, Marco de la Madre Tierra (Pacheco 2013). El contexto emergente de política pública que se encuentra en proceso de implementación, representa una oportunidad para revalorizar la semilla de variedades nativas de papa producidas tradicionalmente por pequeños agricultores, los conocimientos y saberes locales que junto a sus valores culturales y sociales hacen al sistema tradicional de producción que alimenta a la gran mayoría de los bolivianos.

A manera de conclusión se puede indicar que:

Las Familias semilleristas especializadas, los hombres y mujeres involucrados en el proceso, como productores, rescatadores y proveedores de diversidad, desarrollaron esta actividad por generaciones, pero ante los incentivos y desincentivos actuales, cabe la pregunta: hasta qué punto lo pueden seguir haciendo?

Es importante ampliar los incentivos actuales, en el ámbito sociocultural promoviendo el reconocimiento de la experiencia de los semilleristas a través de, por ejemplo, su inclusión en la normativa oficial nacional y/o también más en el ámbito local a través normativas municipales o regionales.

Se deben generar políticas públicas locales para evitar una mayor degradación de los suelos por la ampliación de los problemas fitosanitarios, y promover la protección de los mismos con normas locales, municipales y regionales.

Es deseable ampliar los incentivos económicos, fortaleciendo las capacidades de comercialización de los productores semilleristas, de manera que puedan ingresar al mercado con las destrezas necesarias para establecer negocios de semilla con precios diferenciados respecto a la papa consumo. Es por lo tanto esencial realizar una mayor gestión y control de los costos de producción para incrementar la eficiencia y posicionamiento de la semilla de papa en el mercado.

\section{Referencias citadas}

Aramayo J. (2007). Control de costos de producción para una gestión eficiente caso: pequeño productor de semilla de papa en Cochabamba. Instituto de Estudios Socioeconómicos IESE Universidad Mayor de San Simón UMSS. Cochabamba, Bolivia. Disponible en: http://promex.iese.umss.edu.bo/uploads/d ocs/articulo_1275658447.pdf

Bentley J.; Paz A., Juanes G.; Quiruchi J.L.; Martínez J. (2002). La Semilla Artesanal de Chuquisaca: Un Sistema Semi-Formal, Creativo y Funcional. Proyecto Manejo Integrado de la Marchitez Bacteriana. DFID-PROINPACIP-CABI. Fundación PROINPA, Cochabamba, Bolivia. Disponible en: http://www.jefferybentley.com/Semilleris tas\%20de\%20Chuquisaca.pdf.

Castillo J.A.; Plata G. (2016). The expansion of brown rot disease throughout Bolivia: possible role of climate change. Can. J. Microbiol. 62: 17 dx.doi.org/10.1139/cjm-2015-0665.

Conlago M.; Montesdeoca F.; Mayorga M.; Yumisaca F.; Antezana I.; AndradePiedra J. (2011). Gender relationships in production and commercialization of 
potato seed with small-scale farmers in the Central Andes of Ecuador. En: Devaux A.; Ordinola M. and Horton D. (Eds.) Innovation for Development: The Papa Andina Experience. International Potato Center, Lima, Perú. 346-353 p.

De Hann S. (2009). Potato Diversity at Height: multiple dimensions of farmerdriven in-situ conservation in the Andes. $\mathrm{PhD}$ thesis Wageningen University, The Netherlands, 2009.

Díaz E.; Azurdia C. (2001). El papel de la mujer en la conservación de los recursos genéticos del maíz - Guatemala. FAO Organización de las Naciones Unidas para la Agricultura y la Alimentación. IPGRI - Instituto Internacional para los Recursos Fitogenéticos. Roma. Disponible en: http://www.fao.org/3/ay3841s.pdf

Hidalgo O.; Marca J.; Palomino L. (1997). Producción de Semilla Prebásica y Básica usando Métodos de Multiplicación Acelerada. Manual de capacitación Fascículo 4.3. Centro Internacional de la Papa. Lima, Perú.

INE (2016). Estadísticas por actividad económica. Consulta 07 junio 2016: http://www.ine.gob.bo/indice/general.asp $\mathrm{x}$ ?codigo $=40104$

Jarvis A., A. Lane and R.J.Hijmans. (2008). The effect of climate change on crop wild relatives. Agriculture, Ecosystem \& Environment 126:13-23.
Pacheco D. (2013). Vivir Bien en armonía con la Madre Tierra: una propuesta para el cambio de las relaciones globales entre los seres humanos y la naturaleza. Universidad de la Cordillera/ Fundación de la Cordillera, La Paz, Bolivia.

Rioja R., Barea O. (2004). Manual para la producción de semilla de papa. Fundación PROINPA. Cochabamba, Bolivia.

Plata, G.; Gandarillas, A. \& Cadima, X. (2016). Certified potato seed production supported by soil diagnostics techniques. Poster presented at Plant and Microbe Cold Adaptation meeting 22-25 May, Seatle, Washington, USA.

Tapia M.; De la Torre A. (1997). La mujer campesina y las semillas andinas: Género y el manejo de los recursos genéticos. IPGRI - Instituto Internacional para los Recursos Fitogenéticos. FAO Organización de las Naciones Unidas para la Agricultura y la Alimentación. Disponible en: http://www.fao.org/docrep/x0227s/x0227 s00.htm

Thiele G. (1999). Informal potato seed systems in the Andes: Why are they important and what should we do with them? World development 27(1): 83-99.

Zeballos H., Balderrama F., Condori B., Blajos J. (2009). Economía de la papa en Bolivia (1998 -2007). Fundación PROINPA. Cochabamba Bolivia. 